Published as: Antrop, M. (2014), Interpreting diversity in the European landscape. A comment on Perspective Essays by Agnoletti and Schnitzler. Landscape and Urban Planning, vol. 126, 81-83.

\title{
Interpreting diversity in the European landscape. A comment on Perspective Essays by Agnoletti and Schnitzler
}

\author{
Marc Antrop \\ Landscape Research, Department of Geography, Ghent University \\ Krijgslaan 281 S8, B9000 Ghent, Belgium
}

\begin{abstract}
The essays by Agnoletti and Schnitzler illustrate two discourses regarding the management of vanishing landscapes in Europe. Schnitzler uses an ecological discourse and argues that land abandonment offers opportunities to improve biodiversity. Agnoletti follows a semiotic discourse and sees land abandonment as degradation, causing loss of cultural diversity. Both authors have different conceptions of diversity, but recognize history and traditional practices as important management factors. They focus on rural and forest landscapes and make no link to specific cultural traditions and values when it comes to management. However, changing lifestyles, urbanization and tourism affect all landscapes and polarize European geographical space as a whole. Therefore, the European Landscape Convention proposed a holistic and participatory approach. Perspectives on managing landscapes and diversity vary with the cultural context. European languages express subtle differences in the intimate relationship between landscape and local customs and cultural values that also should be taken into account.
\end{abstract}

Keywords: European Landscape Convention; semiotics; management; land abandonment; change 
Essays provide an ideal means to express personal views on complex matters that

2 encompass different domains of knowledge and research. They help to formulate more

3 clearly one's perspective based on knowledge obtained from facts and personal experiences

4 in dealing with the subject. This certainly holds for visions about landscape planning and

5 management in Europe.

6 The essays by Mauro Agnoletti and Annik Schnitzler presented in this volume are

7 two good examples. At first sight, they represent opposing views about how to deal with the

8 changes rapidly affecting the landscapes in Europe, particularly with respect to issues of

9 diversity and sustainability. The authors' common central question is: how should we

10 manage vast areas of landscapes that become abandoned by people who created and

11 maintained them?

12 Both essays focus on rural and forest landscapes and do not discuss urban,

13 industrial, or coastal landscapes, or the urbanized countryside. They restrict their

14 reflections to landscapes as a product of a varied culture and a long history and which are

15 sometimes called traditional landscapes bearing important natural or heritage values.

16 However, their approach is slightly different. Schnitzler essentially speaks of nature and

17 forest and rarely uses the word landscape. Agnoletti speaks of the rural landscape in a sense

18 typical of the practice of human sciences in Europe.

19 Schnitzler sees the continuing process of land abandonment as a unique opportunity

20 for re-wilding Europe on a large scale. Her perspective follows in the long tradition of

21 nature conservation and principles of ecological management aiming to maintain or

22 improve biodiversity. 
Agnoletti's perspective also deals with landscape conservation, but looks at land

24 abandonment as a process of degradation of traditional rural landscapes, causing a loss of

25 "cultural diversity," which characterizes the European landscape and is essential for the

26 identity of places and for aesthetic values. Hence, in his perspective landscape conservation

27 has to address heritage values contained in the landscape that are not only beneficial for

28 biodiversity, but also essential for the social and cultural identities of people.

29 So, the opposing views relate essentially to the meaning and interpretation of

30 diversity in a landscape context.

31 Essentially, they represent two approaches, which Denis Cosgrove (2003) described

32 as the ecological and semiotic discourse. The term discourse is appropriate here as both

33 authors present their cases and argumentation from their personal experience and

34 expertise. Although both attempt to transcend their disciplinary background to cope with

35 the strong interdisciplinary and even transdisciplinary demands in landscape planning in

36 Europe, their perspectives remain somewhat biased or narrowed, creating the opposing

37 views.

38 I will first summarize the common problem both authors address and broaden

39 somewhat the context of the problem in the European perspective. Next, I will comment on

40 the subtle differences in the concepts of landscape and diversity that are used. Finally, I will

41 present some points for further debate and associated issues that I feel are missing in their

42 prespectives.

44 The common problem: how to manage abandoned landscapes? 
First, there is the concern to deal with the ongoing important landscape changes. As

46 in most parts of the world, European landscapes are transforming increasingly faster,

47 driven by global forces both natural and cultural. At least in Europe, climatic change has

48 become accepted as reality, maybe even more in people's minds than in scientific facts. The

49 very diverse social life and culture in Europe now evolves by global, mainly economic

50 forces. Geographic space is becoming severely polarized between highly urbanized nodes

51 and vast areas that are marginalized and ultimately abandoned. The "urban metropolitan

52 zones," as European institutions call them, are still expanding, forming very complex and

53 multifunctional areas with extreme densities of people, activities and infrastructure. They

54 develop at locations that have advantages in the global economic network. On the other

55 side, areas of marginalization are situated in the economic periphery in what was often

56 once densely inhabited countryside. Here, rural and pastoral landscapes become

57 abandoned and forest takes over. During the whole history of humankind, population size

58 in relation to the environment has been a critical factor in the vulnerability of societies and

59 the change of the landscape. Recently, Zhang et al. (2011) demonstrated global climatic

60 changes during history affected human population dynamics and crisis.

61 Second, there is the specific European context when dealing with landscape and

62 diversity. Both authors recognize the great variety of landscapes and management practices

63 in Europe. Both also agree that history was determinative in the development of different

64 landscape trajectories and types. However, what I missed in both discourses is the

65 recognition that Europe's diversity is essentially formed by different traditions of ethnically

66 different communities, having specific relationships and rights with their land. This is

67 reflected in the diversity of languages and local customs concerning the use of land. The 
68 essential meaning of the word landscape differs in subtle ways between the different

69 tongues, subtleties that are omitted totally when translated in the international term

70 "landscape." Different authors show that the meaning of the landscape in Europe is

71 intimately linked to local customs, laws and social structures and also to memories and

72 beliefs (Olwig, 2013, Lüghinbühl 2012, Schama 1995).

73 These multiple, deeply rooted meanings of landscape expressed through this shared

74 term are one reason why it has been so difficult to broaden the concept of diversity in

75 ecological discourse to encompass more than biodiversity.

76 The First Assessment of the European Environment, the Dobřís sssessment, links the

77 transformation of the rural landscapes to the loss of richness and diversity, which are

78 considered "a distinctive feature of the European continent" and "characteristic for the

79 identity of countries, regions and local areas" (EEA 1995). Two aspects were recognized:

80 the growing speed and magnitude of the ongoing changes, and the traditional cultural

81 landscapes becoming disturbed and lost.

82 Inspired by this report, the Council of Europe formulated the European Landscape

83 Convention (ELC) (Council of Europe 2000). Since the ELC entered into force in 2004, it has

84 had a growing impact on landscape research and policy. This is remarkable as the

85 Convention has no legal basis such as EU-directives have and no financial means are

86 provided. The Convention introduces a formal definition of the landscape, as well as a series

87 of recommendations, which give a common and international basis for research and action.

88 It is important to remember that the ELC-definition of landscape is not only a consensus

89 between the ministers of the members of the Council of Europe, but is also supported by 
90 positive recommendations of the committees on biological and landscape diversity (CO-

91 DBP) and cultural heritage (CC-PAT) (Council of Europe 1999).

92 Although the ELC offers definitions that help co-operation in landscape policy at the

93 European scale, it does not specify how its measures should be interpreted and applied in

94 national legislation. Each participating country is responsible for implementing the ELC

95 considering the international obligations, in particular EU directives such as the Common

96 Agricultural Policy (CAP), Natura 2000, the Habitats Directive, and other international

97 conventions such as UNESCO World Heritage Convention and Agenda 21 and Natura 2000.

98 Although the EU has no direct authority on landscape policy, many directives have

99 indirectly had important impacts on landscape change. Primdahl and Swaffield (2010)

100 showed that dynamics of rural landscape are fundamentally controlled by the two

101 international and opposing agendas: the WTO's open market agenda and the UN's

102 Sustainable Development Agenda 21.

103 The ELC also considers landscape as a human right and emphasizes the importance

104 of participation by the public in assessing values and defining policy (Jones and Stenseke

105 2011). The public is defined in a very broad sense and includes both local residents

106 (insiders) and other potential users (outsiders) of the landscape. In Europe, where more

107 than $80 \%$ of the population lives and works in urban places, this means that landscape

108 values and services get new meanings and the economic dimension of landscape is

109 becoming increasingly important (van der Heide and Heijman 2013). Public participation in

110 decision-making is a slow process and implementing policy is lagging behind the real

111 changes in the landscape. 
113 general and regional landscape policy and management in Europe. Concerning

114 transdisciplinary involvement of the public, both essays focus on the levels of informing and

115 awareness-raising. Contrary to the holistic scope of the ELC, which "applies to the entire

116 territory [...] and covers natural, rural, urban and peri-urban areas" and "concerns

117 landscapes that might be considered outstanding as well as everyday or degraded

118 landscapes" (art.2), both essays focus on particular landscapes in much the same way as do

119 other international conventions and directives.

\section{What diversity?}

122 The opposing views in both essays are essentially different approaches to the

123 concept and meaning of diversity. Agnoletti sees the focus on biodiversity as a problem and

124 suggests widening the concept at the "landscape scale" as "biocultural diversity." Schnitzler

125 focuses on the probable, largely unpredictable effects on species diversity due to a large

126 scale re-wilding processes. To some degree, both authors agree on the importance of the

127 historic development of traditional landscapes (of all kinds) resulting in diverse and

128 sustainable landscapes. Also, recent landscape changes due to globalizing forces such as

129 urbanization are seen as threats to diversity and both authors address the difficulty in

130 conserving existing diversity.

131 In its most basic sense, diversity simply means being composed of differing

132 elements, which is one of the basic characteristics of landscapes. In the context of

133 landscape, adjectives define more specific meanings: biodiversity, cultural diversity,

134 landscape diversity. The concept also implies some notion of measurement: low diversity 
135 considered bad and high diversity as good. This makes diversity not just an attribute

136 describing qualities, but also an indicator allowing some quantification. However,

137 combining assessments of all "differing elements" to create a transparent and usable

138 indicator remains impossible. Reducing diversity in the context of landscape to biodiversity

139 alone is, therefore, not an option.

\section{Points of further discussion}

142 Both essays stress the importance of continuing research. A lot remains unknown

143 and a lot of uncertainty is involved in the ongoing natural and social processes and

144 decision-making. Some examples are addressed in both essays, such as the impact of exotic

145 invasive species, climate changes and economic crisis.

146 Along with the vanishing of the traditional rural and pastoral landscapes, the

147 management practices of the communities that created these landscapes are also becoming

148 lost. The importance of these traditional management practices for diversity and

149 sustainability has been demonstrated (Emanuelsson 2009, Austad 2000). Increasingly

150 faster changes make the study of traditional cultural landscapes even more urgent, almost

151 similar to archaeological rescue excavations.

152 However, it is also clear that the vanishing of traditional practices is irreversible and

153 new management models need to be developed that incorporate heritage knowledge and

154 values as well as preserve natural capital. Changing lifestyle, urbanization, recreation and

155 tourism create new demands for the countryside (Antrop 2005).

156 Managing landscapes over vast areas demand a hierarchical and multi-scale

157 approach. This is already obvious when it comes to dynamic mapping and landscape 
158 visualization. However, when it comes to integrating policy at different scales, many

159 problems remain, in particular when implementing (inter-) national decisions at the local

160 level (Pinto-Correia et al. 2006). 


\section{References}

Agnoletti, M., Rural landscape, environment and culture: Notes on some research trends and management approaches from a European perspective. Landscape and Urban Planning, this volume.

Antrop, M., 2005. Why landscapes of the past are important for the future. Landscape and Urban Planning, 1-2, 21-34.

Austad, I., 2000. The future of traditional agriculture landscapes: retaining desirable qualities. In: Klijn, J., Vos, W. (eds.), 2000. From Landscape Ecology to Landscape Science. WLO, Wageningen, Kluwer Academic Publ., pp. 43-56

Cosgrove, D., 2003. Landscape: ecology and semiosis. In: Palang, H. \& Fry, G., 2003. Landscape Interfaces. Cultural heritage in changing landscapes. Kluwer Academic Publishers, Dordrecht, 15-20 pp.

Council of Europe, 1999. Opinion of the Cultural Heritage Committee (CC-PAT) and the Committee for the activities of the Council of Europe in the field of biological and landscape diversity (CO-DBP) on the draft European Landscape Convention and necessary procedures, for the attention of the Committee of Ministers, in response to the ad hoc terms of reference resulting from the decision CM/703/180998, adopted respectively on 17 February and 19 April 1999.Dcoument CM(99)84.

Council of Europe, 2000. European Landscape Convention. CETS No.:176. http://conventions.coe.int/Treaty/Commun/QueVoulezVous.asp?NT=176\&CL=ENG

EEA 1995. Europe's Environment - The Dobris Assessment. http://www.eea.europa.eu/publications/92-826-5409-5

Emanuelsson, U., 2009. The Rural Landscapes of Europe. How man has shaped European nature. The Swedish Research Council Formas.

Jones, M. \& Stenseke, M. (eds) 2011. The European Landscape Convention. Challenges of Participation. Springer, Landscape Series, Vol. 13.

Luginbühl, Y., 2012. La mise en scène du monde. Construction du paysage européen. CRNS Editions, Paris.

Olwig K., 2013. The law of landscape and the landscape of law: the things that matter. In: Howard, P., Thompson, I., Waterton, E. (eds.), The Routledge Compagnion to Landscape Studies. Routledge, London, pp. 253-262.

Pinto-Correia,T. Gustavsson, R., Pirnat, J., 2006. Bridging the gap between centrally defined policies and local decisions - Towards more sensitive and creative rural landscape management. Landscape Ecology, 21:3, 333-346.

Primdahl, J. \& Swaffield, S. (eds), 2010. Globalisation and agricultural landscapes change patterns and policy trends in developed countries. Cambridge University Press, Cambridge.

Schama, S., 1995. Landscape and Memory. A.Knopf, New York.

Schnitzler, A., Towards a new European wilderness: Embracing unmanaged forest growth and the decolonization of nature. Landscape and Urban Planning, this volume.

van der Heide, M. and Heijman, W.J.M. (eds), 2013. The Economic Value of Landscapes. Routledge Studies in Ecological Economics.

Zhang, D.D., Lee H.F., Cong Wang, Baosheng Li, Qing Pei, Zhang J., Ylun An 2011. Causality analysis of climate change and large-scale human crisis. PNAS, vol.108,42, pp.1729617301." www.pnas.org:cgi/doi/10.1073/pnas.1104268108" 